7. Reprod. Fert. (1972) 29, 395-406

\title{
FERTILIZATION IN THE PIG: SEQUENCE OF NUCLEAR AND CYTOPLASMIC EVENTS
}

\author{
R. H. F. HUNTER* \\ Station Centrale de Physiologie Animale, Institut National de la Recherche Agronomique, \\ 78-Jouy-en-Fosas, France
}

(Received 28th April 1971, accepted 29th Fune 1971)

Summary. The timing of sperm penetration, pronuclear formation and syngamy was examined in twenty-four gilts in which ovulation had been controlled precisely by means of an injection of HCG given during prooestrus. Animals were mated at the time of ovulation and eggs recovered at autopsy exactly 3, 4, 5 or $6 \mathrm{hr}$ later.

Twenty of the twenty-four animals $(83 \%)$ yielded some penetrated eggs, a total of 234 eggs being examined. The mean number of spermatozoa attached to or within the zona pellucida increased progressively from 6.8 (range 1 to 25)/egg at $3 \mathrm{hr}$ to 109.2 (range 1 to 466 ) some $6 \mathrm{hr}$ after mating. Likewise, the proportion of eggs classified as fertilized increased from $23.7 \%$ at $3 \mathrm{hr}$ to $71.9 \%$ by $5 \mathrm{hr}$ after mating. Developing pronuclei were observed at $4 \mathrm{hr}$ and apposing pronuclei within $5 \mathrm{hr}$ of mating, but most of the penetrated eggs examined at these intervals were in anaphase or telophase of the second meiotic division.

The results emphasize that under conditions of induced ovulation, a population of capacitated spermatozoa first becomes available in the Fallopian tubes of oestrous pigs within 2 to $3 \mathrm{hr}$ of semen deposition by way of the cervix. It is suggested that the sequence of events leading to sperm penetration may be accelerated following injection of HCG during pro-oestrus and mating at the time of ovulation.

\section{INTRODUCTION}

Information on the timing of the various stages of fertilization from sperm penetration through to syngamy in eggs of the large domestic species is available for both the sheep and cow (Thibault, 1967). By contrast, details of the processes of pronuclear development and early cleavage in pigs come from studies in which the stages of development were related only to an estimate of the time of ovulation (Pitkjanen, 1955; Thibault, 1959; Hancock, 1961), which in turn was based on determination of the onset of oestrus. Precise control of the time of ovulation by means of injection of HCG has been employed in a number of recent experiments concerning fertilization in pigs (Dziuk \& Polge, 1962; Polge \& Dziuk, 1965; Baker, Dziuk \& Norton, 1967; Hunter, 1967a, b; Day \& Polge, 1968; Hancock \& Buttle, 1968). However, chronological details of the

* Present address: School of Agriculture, University of Edinburgh, West Mains Road, Edinburgh 9. 
stages of fertilization using induced ovulation have yet to be documented, although a comprehensive study on the timing of sperm penetration in relation to ovulation and insemination has been presented (Hunter \& Dziuk, 1968).

The following experiments have examined the sequence of events during fertilization in mature pigs in which eggs of known postovulatory age were recovered at specific intervals after mating. The results also confirm and extend earlier findings on the timing of boar sperm capacitation and the penetration of pig eggs (Hunter \& Dziuk, 1968).

\section{MATERIAL AND METHODS}

\section{Experimental animals}

Twenty-four Large White gilts weighing approximately 80 to $140 \mathrm{~kg}$ and aged between 6 and 9 months, were used in this study. They were penned and fed in groups of three to five in an indoor piggery, and tested for oestrus with a boar at 07.30 hours and 16.30 hours. None of the animals had been used previously for experimental work.

\section{Induction of ovulation}

The time of ovulation was controlled by a single intramuscular injection of 500 i.u. HGG (Intergonan B, Organon) in $5 \mathrm{ml}$ sterile saline given during late pro-oestrus. This stage was indicated by the swelling and colour of the vulva, as well as by reference to the length of the previous oestrous cycle in fifteen of the gilts. Designating the first day of oestrus as Day 0, these latter animals were injected on Day 19 or 20 of the cycle. It was confirmed that animals would not stand to the boar at this time. On the basis of previous studies conducted at this Institute (unpublished observations), ovulation was assumed to occur $44 \mathrm{hr}$ after the HGG injection.

\section{Procedure at mating}

Animals were served by one of two Large White boars $44 \pm 1 \mathrm{hr}$ after the injection of gonadotrophin. To avoid imposing conditions of stress following mating, the gilts then remained in their pens until 10 min before slaughter, at which time they were taken to the Institute's abattoir.

\section{Post-mortem examination}

The mated females were stunned electrically at $3,4,5$ or $6 \mathrm{hr}( \pm 6 \mathrm{~min})$ after mating. The reproductive tract was removed following bleeding but before immersion of the carcase in the scalding tank. After rapidly dissecting the Fallopian tubes free of the mesosalpinx and uterine cornua, their contents were carefully flushed from the ovarian end with physiological saline $(0.9 \% \mathrm{NaCl})$ into polythene Petri dishes. The eggs were located using a binocular microscope $(\times 12.5)$ and transferred to embryological watch glasses containing Bouin-Hollande's solution. After 24 to $48 \mathrm{hr}$ of fixation, the eggs were included in agar, dehydrated with alcohol, and embedded in paraffin wax (Thibault, 1949). The blocks were sectioned serially at 8 to $10 \mu \mathrm{m}$ and stained with Regaud's haematoxylin. Detailed examination of the sections was made using 
bright field microscopy, particular attention being paid to the number of spermatozoa on and in the zona pellucida. The location and morphology of vitelline sperm heads or pronuclear structures were noted, as was the configuration of the second meiotic spindle. Eggs, in which the ooplasm had been penetrated by a spermatozoon and the second meiotic division had progressed to anaphase or telophase, have been classified as fertilized.

\section{RESULTS}

All animals exhibited oestrus within $40 \mathrm{hr}$ of the HCG injection and stood to the boar at the time scheduled for mating. The mean number of ovulations per animal counted at autopsy was 11.8 , with a range from 9 to 19 . A total of four Graafian follicles of 7 to $9 \mathrm{~mm}$ diameter was observed in three animals; these may have represented instances of incomplete ovulation. Details of the number of recent ovulations together with the proportion of eggs recovered are presented in Table 1 , and indicate that egg recovery did not differ significantly with the interval elapsing between mating and autopsy.

Twenty of the twenty-four animals $(83 \%)$ had some fertilized eggs at autopsy (Table 1) but, because the time between mating and the recovery of eggs never exceeded $6 \mathrm{hr}$, it is possible that this percentage underestimates the proportion of animals that would have conceived. The number and proportion of eggs having one or more spermatozoa attached to or within the zona pellucida varied considerably with the interval from mating (Table 2). However, in eggs with one or more spermatozoa, the mean number and range of spermatozoa per egg increased progressively over the four intervals examined (Table 1).

An analysis of the proportion of eggs penetrated and fertilized is presented in Table 2. The findings at each of the four intervals from mating are considered separately below.

\section{Eggs recovered $3 \mathrm{hr}$ after mating}

All the recovered eggs were completely denuded of cells of the cumulus oophorus and corona radiata in four of the animals. The remaining two animals yielded five eggs in a loose matrix of cumulus and corona cells, despite the presence of spermatozoa on a proportion of the eggs in both these instances.

Four of the six animals had some penetrated eggs (Table 1), but spermatozoa could not be located in the zona pellucida of the eighteen eggs examined from the other two animals. Spermatozoa were found attached to or within the zona pellucida of thirty-nine of the fifty-nine recovered eggs. The number of spermatozoa counted on or in the zonae of these eggs ranged from one to twenty-five, with a mean of $6.8 / \mathrm{egg}$. An analysis of the developmental stages of all the eggs is given in Table 2, which shows that anaphase or telophase of the second meiotic division, together with a sperm head in the vitellus (Pl. 1, Figs. 1 to 9 ), was present in fourteen $(24 \%$ ) of the eggs. A further four eggs each contained a spermatozoon in the perivitelline space, raising the proportion of eggs penetrated within $3 \mathrm{hr}$ of mating to $31 \%$.

Evidence for rotation of the meiotic spindle before formation of the second polar body was not found in this series of eggs. 







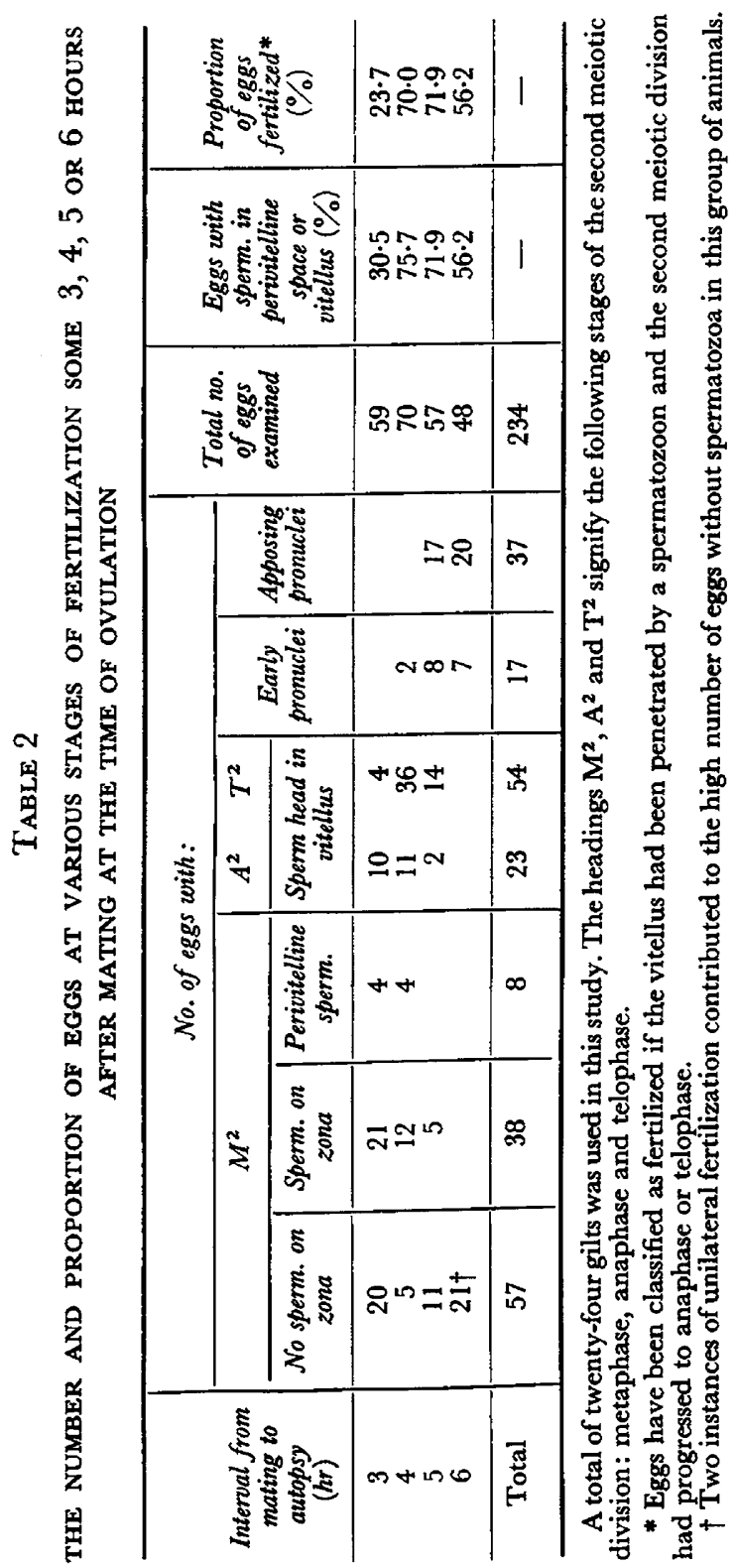


Eggs recovered $4 \mathrm{hr}$ after mating

Some completely denuded eggs were obtained from all animals in this group, but traces of cumulus cells were still associated with two eggs in one gilt and five eggs in another. Penetrated eggs were present in both of these animals.

A total of seventy eggs was examined, the number of eggs per animal varying from eight to thirteen. Spermatozoa were attached to or had penetrated the zona pellucida of sixty-five of these eggs (Table 1), the mean number of such spermatozoa being $26 \cdot 4 / \mathrm{egg}$. The most advanced development observed in this group of eggs was that termed the early pronuclear stage (Pl. 2, Figs. 10 and 11). Two animals each yielded a single egg at this stage (Table 2), in which both the male and the female elements were completely surrounded by a nuclear membrane and the chromatin in the female pronucleus was orientated towards that in the male. These pronuclei, which were located subcentrally, were judged to be less than $\frac{1}{8}$ the volume that the mature structures would attain. The sperm mid-piece was clearly associated with the male pronucleus in one of these eggs, and in a number of other instances, a considerable proportion of the sperm tail could be detected in the cytoplasm.

The great majority of the penetrated eggs $(88 \%)$ in this group were in anaphase or telophase of the second meiotic division (Table 2), and exhibited enlarged sperm heads occupying a peripheral position in the cytoplasm. The vitelline membrane was elevated around the fertilizing spermatozoon at this stage (Pl. 1, Figs. 1 to 3 ), and a structure that resembled a swelling of nuclear material was often closely associated with the posterior region of the sperm head (Pl. 1, Figs. 4 to 6). A reorganization of the cytoplasm had taken place around the complex formed by these structures and the remainder of the sperm head (Pl. 1, Figs. 5 and 6), and may have represented a fixation artifact or a modification preceding pronucleus formation. The synchrony of sperm penetration was particularly conspicuous in two animals, in which all twenty-nine eggs had either anaphase or telophase arrangements of the meiotic chromosomes.

\section{EXPLANATION OF PLATE 1}

Bright-field photomicrographs of pig eggs recovered from the Fallopian tubes either 3 or $4 \mathrm{hr}$ after mating at the time of ovulation. The eggs were fixed in Bouin-Hollande's solution, sectioned at 8 to $10 \mu \mathrm{m}$ and stained with Regaud's haematoxylin. All figures approx. $\times 1200$.

Figs. 1 to 3. Eggs recovered shortly after entry of the fertilizing spermatozoon into the ooplasm. The vitelline membrane is elevated in the region adjacent to the sperm head, this phenomenon being particularly pronounced in Fig. 3. Note the presence of other spermatozoa embedded in the outer layer of the zona pellucida. The chromosomes of each of these eggs were arranged in anaphase or telophase of the second meiotic division. Figs. 4 to 6 . Transformation of the fertilizing spermatozoon into a male pronucleus is commencing in these figures. The sperm head is still located peripherally in the ooplasm, but the nuclear material has started to swell. De-condensation of this material at the posterior end of the sperm head probably accounts for the 'structure' apparent in this region, although the vacuoles conspicuous in Figs. 5 and 6 may represent fixation artifacts.

Figs. 7 to 9 . Completion of the second meiotic division in recently penetrated eggs corresponding to those shown in Figs. 1 to 6 . This series shows the sequence of events from the radially arranged spindle of late anaphase (Fig. 7) to completion of second polar body formation (Fig. 9). The mid-body of the spindle is clearly visible in Fig. 8, and is seen to be extruded into the perivitelline space with the second polar body in Fig. 9. Note the persistence of the spindle fibres forming a temporary bridge between the polar body and vitellus. 
PI.ATF, 1


(1)aing $1 \%$. 10): 
PL. \TE:
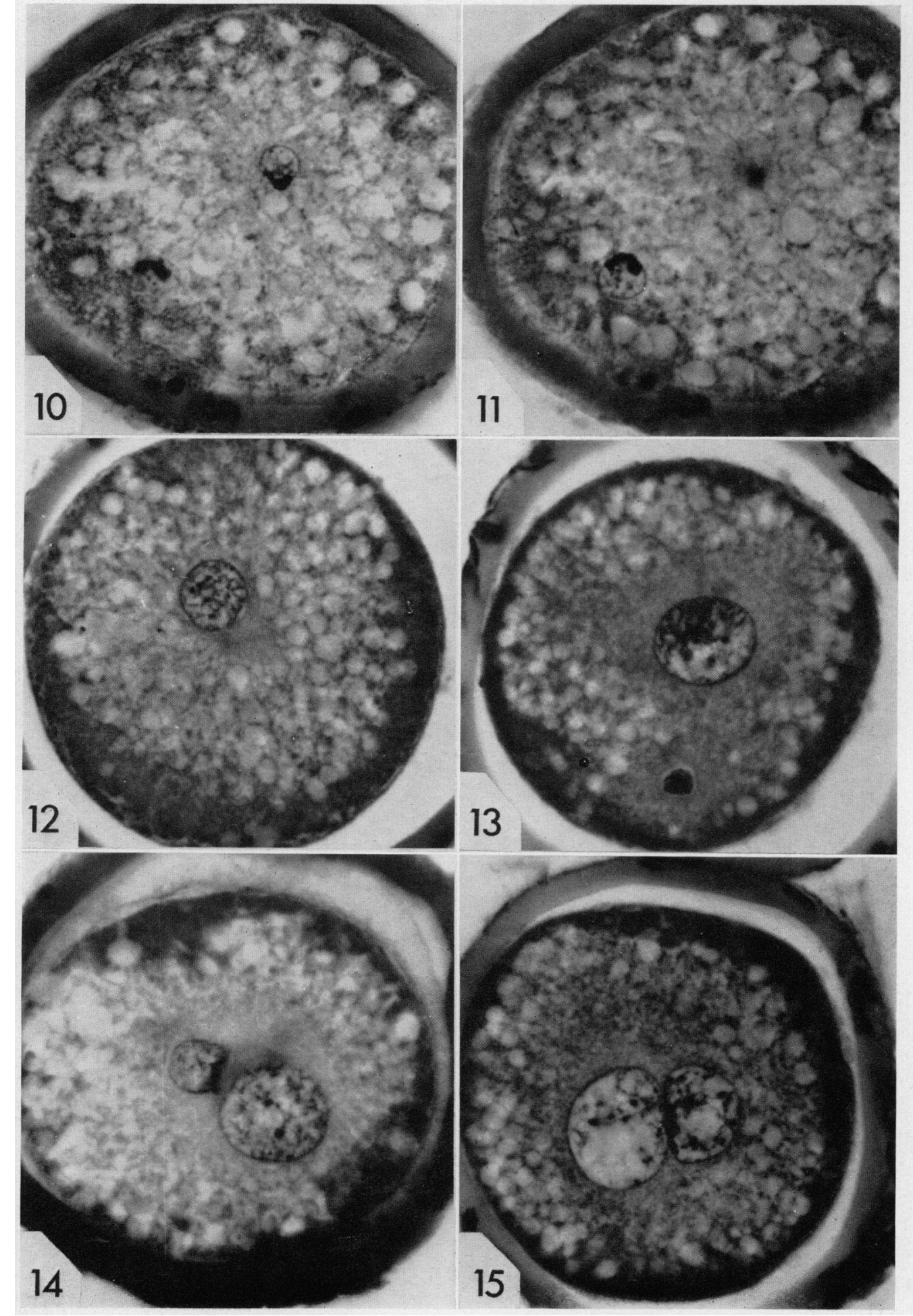
Two instances of dispermy and one instance of trispermy were recorded in this series, in each of which the sperm heads were located peripherally in the cytoplasm and had undergone a degree of swelling.

\section{Eggs recovered $5 \mathrm{hr}$ after mating}

A total of fifty-seven eggs was examined in this series (Table 1). All were completely denuded of their cumulus and corona cells at recovery. Five of the six animals yielded fertilized eggs, but the remaining gilt had nine unfertilized eggs with no detectable spermatozoa.

Spermatozoa were present on or had penetrated the zona pellucida of forty-six of the eggs, in which the mean number of spermatozoa was 71.4/egg (Table 1). Forty-one of these eggs had been fertilized, 39\% showing anaphase or telophase arrangements of the second meiotic spindle whereas the remaining $61 \%$ had already entered the pronuclear stage (Table 2).

Synchrony of development was noted in the eggs of two animals in this series. All ten eggs recovered from one gilt exhibited either anaphase or telophase of the second meiotic spindle together with a swollen sperm head in the cytoplasm. In the second animal, all eleven eggs had reached the pronuclear stage. Three dispermic eggs were identified: two of these were at second meiotic telophase and each contained two swelling sperm heads in the cytoplasm. Fifty-one and sixty spermatozoa, respectively, were counted in the zonae of these eggs. The third was a pronuclear egg in which the first and second polar bodies were clearly distinguishable, and in which a swollen male structure could be detected (Pl. 2, Fig. 13). One hundred and sixty-two spermatozoa were attached to or had penetrated the zona of this egg.

\section{EXPLANATION OF PLATE 2}

Bright-field photomicrographs of pig eggs recovered from the Fallopian tubes between 4 and $6 \mathrm{hr}$ after mating at the time of ovulation. The eggs were fixed in Bouin-Hollande's solution, sectioned at 8 to $10 \mu \mathrm{m}$ and stained with Regaud's haematoxylin. All figures approx. $\times 750$.

Figs. 10 and 11. Sections through the same egg at different focal planes. Formation of the two pronuclei has only just occurred, but each now possesses a complete nuclear membrane. The female pronucleus is situated in the lower hemisphere of the egg towards the darkly staining chromatin of the second polar body. The sperm mid-piece could be detected in the cytoplasm, but lies out of focus above the male pronucleus.

FIG. 12. Section through a normally fertilized egg showing only the male pronucleus which was not yet in apposition with its female counterpart. The vitelline globules have undergone a degree of reorganization, and there is a suggestion of a rearrangement of the cytoplasm between the male pronucleus and the centre of the egg.

Fig. 13. A dispermic pronuclear egg in which the female pronucleus is distinct, but the adjoining male pronucleus lies at another plane of focus. The darkly staining body in the lower portion of the egg is a slightly swollen sperm head. Again, note the reorganization of the cytoplasmic components, with the finely granular material becoming centred around the nuclear structures.

Fig. 14. Section to show pronuclear arrangement shortly before apposition occurs. The female pronucleus appears considerably smaller than the male in this section, but this is partially because its largest diameter lies below the plane of section. Note the aggregation of chromatin in the female pronucleus, and also the change in disposition of the vitelline yolk material.

Fig. 15. A normally fertilized egg showing the two mature pronuclei in apposition in the centre of the vitellus, the male pronucleus being slightly larger. A network of chromatin is present at this stage, but the heavy condensation that precedes chromosome formation has not yet occurred and the pronuclear membranes are still intact. Note the accessory spermatozoa in the zona pellucida. 
Eggs recovered $6 \mathrm{hr}$ after mating

The six animals in this series yielded a total of forty-eight eggs, of which ten eggs obtained from two animals still possessed some adherent cumulus and corona cells. A condition of unilateral fertilization was observed in both these instances, completely denuded fertilized eggs being flushed from one Fallopian tube whereas no spermatozoa could be detected about the eggs from the other tube. A third animal had unfertilized eggs in both Fallopian tubes (Table 1), but no obstruction of the tract was found to account for this situation.

Twenty-seven of the recovered eggs $(56 \%)$ had spermatozoa attached to or within the zona pellucida, the mean number of such spermatozoa being $109 \cdot 2 / \mathrm{egg}$ (Table 1). The twenty-one unpenetrated eggs still showed a compact arrangement of chromosomes on the metaphase plate, whereas all twenty-seven activated eggs were at the pronuclear stage. In these latter eggs, the fertilizing spermatozoon had undergone transformation from a swollen sperm head into a distinct pronucleus, about which a reorientation of finely textured ooplasm could be detected in several instances (Pl. 2, Fig. 12).

The pronuclear membranes were clearly in apposition in $41.7 \%$ of the eggs, and some condensation of chromatin had taken place, particularly towards the interface of the pronuclear membranes (Pl. 2, Fig. 15). But there was no suggestion as yet of formation of individual chromosomes or dissolution of the pronuclear membranes.

Two dispermic eggs which were at the stage of pronuclear apposition were obtained in this group, and each possessed a large accessory male pronucleus close to the vitelline membrane. First and second polar bodies were detected on both these eggs, and totals of 224 and 289 spermatozoa, respectively, were counted on the two zonae. Evidence suggestive of digynic fertilization was also found in two eggs, each of which contained three large pronuclei. Two of the pronuclei were centrally placed within the egg, whereas the third remained peripheral. Second polar bodies could not be located on these eggs.

\section{DISCUSSION}

The findings in the present study demonstrate clearly that, under conditions of induced ovulation, boar spermatozoa can reach and penetrate into the ooplasm and cause resumption of meiosis within $3 \mathrm{hr}$ of natural mating. These results, therefore, emphasize that a population of capacitated spermatozoa first becomes available in the Fallopian tubes within 2 to $3 \mathrm{hr}$ of semen deposition by way of the cervix, thereby endorsing previous observations made after artificial insemination of gilts (Hunter \& Dziuk, 1968). By contrast, it has been found that following surgical introduction of whole semen directly into the Fallopian tubes by way of the isthmus, penetrated pig eggs are not commonly observed for some $5 \mathrm{hr}$ (Polge, personal communication), and failure to achieve capacitation may reasonably be implicated in this delay. The extremely short interval required for capacitation in oestrous pigs is, therefore, best demonstrated when spermatozoa are exposed sequentially to the different regions of the female reproductive tract, as occurs after mating. Because the bulk of the seminal plasma appears to be absorbed rapidly by the uterus in oestrous pigs (du 
Mesnil du Buisson \& Dauzier, 1955a; Mann, Polge \& Rowson, 1956; Rigby, 1964; Lovell \& Getty, 1968) and may not pass beyond the utero-tubal junction, the technique of instillation of whole semen directly into the Fallopian tubes represents a major departure from the physiological situation. The presence of seminal plasma at this site might, therefore, be expected to disturb the timing of capacitation and sperm penetration into the egg.

Conclusions can now be drawn as to the rate of pronuclear formation and migration in pig eggs, on the basis of finding sperm penetration into the ooplasm $3 \mathrm{hr}$ after mating and mature male and female pronuclei in central apposition $6 \mathrm{hr}$ after mating. Evolution of the sperm head from a slightly swollen structure located peripherally into an 'early' pronucleus with intact membrane apparently requires approximately $\mathrm{I}_{\frac{1}{2}}$ to $2 \mathrm{hr}$. The subsequent development of both male and female elements into mature pronuclei and their migration from a cortical to a central position in the egg may take an hour or more. The observations of Thibault (1959) and Hancock (1961) on spontaneously ovulating pigs in which pronuclear eggs were recovered $5 \frac{3}{4}$ to $6 \mathrm{hr}$ after mating are, therefore, compatible with the finding of penetration and activation of pig eggs $3 \mathrm{hr}$ after mating. Although pronuclear apposition was observed in the present study within $6 \mathrm{hr}$ of mating, pronounced condensation of chromatin and formation of chromosomes were not detected, nor was dissolution of the pronuclear membranes seen. It is probable that the appearance of the two haploid groups of chromosomes and their arrangement at metaphase of the first mitotic spindle would not take place until a further 6 to $8 \mathrm{hr}$ had elapsed. This figure is based on unpublished studies and from the work of Polge (personal communication) in which the first cleavage of pig eggs was not observed until 12 to $14 \mathrm{hr}$ after the estimated time of sperm penetration. The delay undoubtedly includes an interval for completion of DNA duplication, spindle formation, and the first mitotic division.

In the light of recent evidence concerning aspects of capacitation in the rabbit (Soupart, 1966, 1967; Wettemann \& Hafs, 1970), the use of HGG throughout this study to induce ovulation deserves further comment. Whilst it is extremely unlikely that the population of eggs ovulated following injection of this hormone in late pro-oestrus differed significantly from that which would have ovulated spontaneously during oestrus, it is possible that HCG may exert some indirect control over the sequence of events at fertilization. This would be due to its influence on the pattern of ovarian steroid production (see Soupart, 1967), and in particular on the hormonal output of preovulatory Graafian follicles. In a previous study in gilts (Cook \& Hunter, unpublished), relatively large quantities of progesterone were found in follicular fluid $(63.2$ to $66 \mu \mathrm{g} / 100 \mathrm{ml})$ at intervals between 8 and $32 \mathrm{hr}$ after a single injection of $500 \mathrm{i}$.u. HCG given during prooestrus, and some of this fluid presumably enters the Fallopian tube at ovulation. Ovarian steroids have for many years been known to influence the process of capacitation (Chang, 1958), but only recently has it been considered that substances such as progesterone may be acting at the membranous level to induce the acrosome reaction of spermatozoa (Austin, Bavister \& Edwards, 1972). Therefore, under the hormonal conditions that obtain following injection of HCG during pro-oestrus and mating at the time of ovulation, the process of capa- 
citation and the ensuing acrosome reaction may be accelerated, which, in turn, could influence the timing of sperm penetration and fertilization.

The mean number of spermatozoa reaching and attaching to the eggs between 3 and $6 \mathrm{hr}$ after mating increased markedly in this study from 6.8 to 109.2. Although the rate and efficiency of sperm transport has been reported to vary considerably during the period of oestrus in pigs (du Mesnil du Buisson \& Dauzier, 1955b; Ito, Kudo \& Niwa, 1959; Pitkjanen, 1958, 1960), conditions approaching the optimum for rapid sperm transport may have prevailed at the stage of oestrus found in these experiments. All animals were mated at the time of ovulation which would correspond with approximately mid to late oestrus under conditions of spontaneous ovulation, at which time sperm transport to the Fallopian tubes may be most rapid (du Mesnil du Buisson \& Dauzier, 1955b; Ito et al., 1959; Pitkjanen, 1958, 1960). Too much weight cannot be placed on comparisons between groups of the mean numbers of spermatozoa given here, for considerable variation in the number of spermatozoa introduced into the female tract would have occurred with natural mating. Nevertheless, the fact that several spermatozoa may be in contact with the zona pellucida at the time of sperm entry into the vitellus is emphasized, as is the continued increase in numbers of spermatozoa attaching to the eggs for at least the first $6 \mathrm{hr}$ after mating. The synchrony of the early stages of fertilization observed in eggs recovered from several animals may, therefore, be attributable in part to the presence of an adequate number of capacitated spermatozoa in these instances.

In contrast to the situation that exists shortly after ovulation in unmated pigs (unpublished results), very few eggs were recovered in this study with cells of the cumulus oophorus and corona radiata still adherent to the zona pellucida. It is inferred that the population of spermatozoa that reaches the ampulla of the Fallopian tube within an hour of mating (Rodolfo, 1934; Burger, 1952; Ito et al., 1959; Pitkjanen, 1960) is involved in the rapid dispersal of the cumulus and corona cells. However, the finding in both the present and a previous study (Hunter \& Dziuk, 1968) that some penetrated eggs may still possess remnants of the cellular investments indicates that under conditions in which mating or insemination precedes ovulation, spermatozoa can certainly reach and penetrate the zona pellucida before the eggs have become completely divested of their surrounding cumulus. Such a conclusion would be in accordance with the observations of Hancock (1961), who noted that the cumulus cell mass was found around eggs only from sows killed less than $8 \mathrm{hr}$ after mating.

Although the descriptions presented above concern eggs already penetrated and undergoing various phases of the fertilization process, it should be recalled that mainly unfertilized eggs were examined in these experiments; the mean proportion of eggs fertilized during the time interval examined ranged from 24 to $72 \%$. The minimum period following mating or insemination at the time of ovulation that would be required for all the eggs to be penetrated and activated has yet to be determined accurately, but it may well be of the order of $8 \mathrm{hr}$. In any event, variability in the stages of early embryonic development would seem to arise mainly from variation in the timing of penetration (Thibault, 1967). A clear definition of the conditions under which this variation can be minimized would have important practical applications. 


\section{ACKNOWLEDGMENTS}

The author is extremely grateful to Professor C. Thibault for the hospitality of his laboratory, and for commenting on the manuscript.

He would also like to thank Mme Micheline Gérard for preparing sections of the eggs, M. P. Surel for taking care of the animals, and Mr R. J. Patman of the Animal Research Station, Cambridge, for printing the photographs. Professor J. L. Hancock and Dr C. Polge kindly read the manuscript and made a number of valuable suggestions.

\section{REFERENCES}

Austin, C. R., Bavister, B. D. \& Edwards, R. G. (1972) Components of capacitation. In: The Regulation of Mammalian Reproduction; N.I.H. Bethesda Conference, 1970. (In press).

Baker, R. D., Dziuk, P. J. \& Norton, H. W. (1967) Polar body and pronucleus formation in the pig egg. 7. exp. Zool. 164, 491.

Burger, J. F. (1952) Sex physiology of pigs. Onderstepoort 7. vet. Res. Suppl. 2.

Ghang, M. C. (1958) Capacitation of rabbit spermatozoa in the uterus with special reference to the reproductive phases of the female. Endocrinology, 63, 619 .

Day, B. N. \& Polge, C. (1968) Effects of progesterone on fertilization and egg transport in the pig. F. Reprod. Fert. 17, 227.

Du Mesnil du Buisson, F. \& Dauzier, L. (1955a) Distribution et résorption du sperme dans le tractus génital de la truie: survie des spermatozoìdes. Annls Endocr. 16, 413.

Du Mesnil du Bursson, F. \& Dauzier, L. (1955b) La remontee des spermatozoïdes du verrat dans le tractus génital de la truie en oestrus. C. r. Séanc. Soc. Biol. 149, 76.

Dziuk, P. J. \& Polge, C. (1962) Fertility in swine after induced ovulation. 7. Reprod. Fert. 4, 207.

Hancock, J. L. (1961) Fertilization in the pig. F. Reprod. Fert. 2, 307.

HANCOCK, J. L. \& Butrle, H. L. (1968) Tubal transport and fertilization of ova in gonadotrophintreated pigs. 7. Reprod. Fert. 16, 261.

Hunter, R. H. F. (1967a) The effects of delayed insemination on fertilization and early cleavage in the pig. F. Reprod. Fert. 13, 133.

Hunter, R. H. F. (1967b) Polyspermic fertilization in pigs during the luteal phase of the estrous cycle. F. $\exp$. Zool. 165, 451.

Hunter, R. H. F. \& Dziuk, P. J. (1968) Sperm penetration of pig eggs in relation to the timing of ovulation and insemination. 7. Reprod. Fert. 15, 199.

Ito, S., Kudo, A. \& Niwa, T. (1959) Studies on the normal oestrus in swine with special reference to proper time for service. Annls Zootech. Ser. D, Suppl., p. 105.

LOVELL, J. E. \& GETTY, R. (1968) Fate of semen in the uterus of the sow: histologic study of endometrium during the 27 hours after natural service. Am. F. vet. Res. 29, 609.

Mann, T., Polge, G. \& Rowson, L. E. A. (1956) Participation of seminal plasma during the passage of spermatozoa in the female reproductive tract of the pig and horse. F. Endocr. 13, 133.

PitkJanen, I. G. (1955) Ovulation, fertilization and the early stages of embryonic development in pigs. Izo. Akad. Nauk. S.S.S.R., Ser. Biol. 3, 120.

PrtkJanen, I. G. (1958) Some data on the transport of semen in the genital tract of the sow. Trudy pushkin. nauchno-issled. Lab. Razv. sel.'-khoz. Zhivot. 8, 98. (Anim. Breed. Abstr. 27, 929).

Pitrjanen, I. G. (1960) The fate of spermatozoa in the uterus of the sow. Zh. obshch. Biol. 21, 28. (Anim. Breed. Abstr. 28, 299).

Polge, C. \& Dziuk, P. (1965) Recovery of immature eggs penetrated by spermatozoa following induced ovulation in the pig. 7. Reprod. Fert. 9, 357.

Rigby, J. P. (1964) The fate of spermatozoa in the genital tract of the sow following artificial insemin. ation. Proc. 5th int. Congr. Anim. Reprod. Artif. Insem. 4, 421.

Rodolfo, A. (1934) The physiology of reproduction in swine. II. Some observations on mating. Philipp. F. Sci. 55, 13.

SoupART, P. (1966) Effects of human chorionic gonadotrophin on capacitation of rabbit spermatozoa. Nature, Lond. 212, 408.

Soupart, P. (1967) Studies on the hormonal control of rabbit sperm capacitation. F. Reprod. Fert., Suppl. 2, 49 . 
Thibault, C. (1949) L'œuf des mammifères. Son développement parthénogénétique. Annls Sci. nat. Zool. 11, 136.

Thrbauzt, C. (1959) Analyse de la fécondation de l'œuf de la truie après accouplement ou insémination artificielle. Annls Zootech., Suppl. 8, 165.

Thibault, C. (1967) Analyse comparée de la fécondation et de ses anomalies chez la brebis, la vache et la lapine. Annls Biol. Anim. Biochim. Biophys. 7, 5.

WetTemann, R. P. \& HAFs, H. D. (1970) Sperm capacitation after injection of $\mathrm{LH}$ or HGG in rabbits. Prac. Soc. exp. Biol. Med. 133, 1002. 